\title{
Poetry
}

\section{The doctor during death}

Previously published at www.cmaj.ca

Still, cold and clammy.

A gasp here and there, a torment to the souls around. They watch in disbelief, in awe, in question.

He stands there in despair, in panic, without answer.

Pale, hard and taut.

A stare that is deep, but not focused.

They look to someone, above or perhaps below, for action. He stands there motionless, afraid, and idle.

She leaves at last.

A peaceful surrender.

They cry, they pray, they accept.

of I step into the white jacket, reassure, and console.

\section{Vikram Tangri MD}

University of Western Ontario and London Health Sciences Center

Department of Medicine

London, Ont.

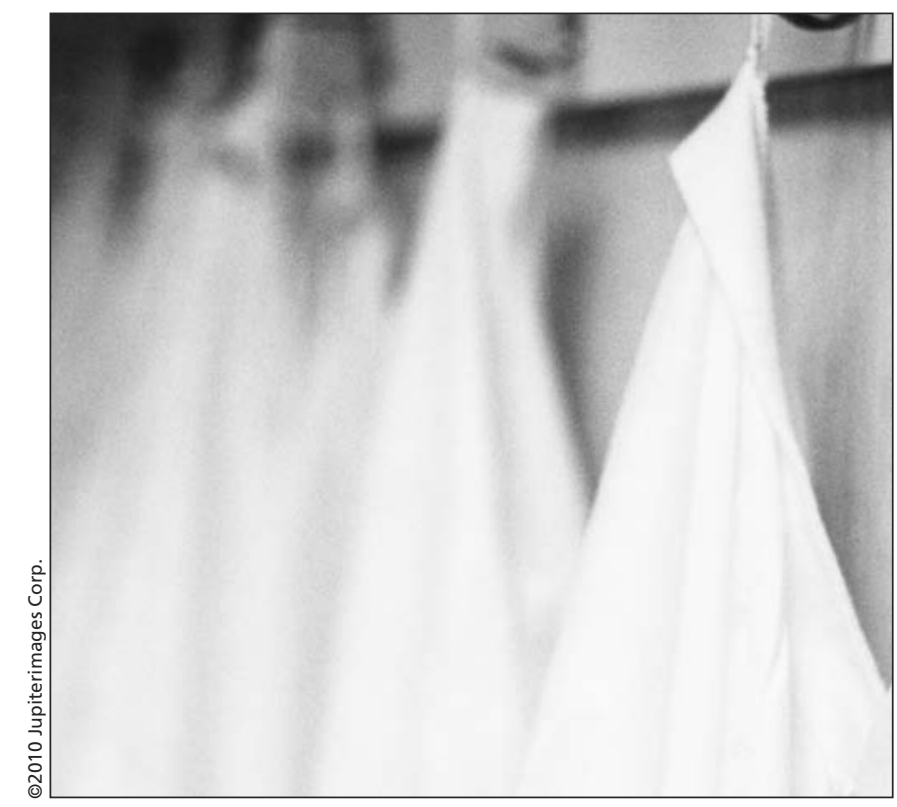

